\title{
PUBLICACIONES CON CONTENIDOS POÉTICOS EN CAN- TABRIA, A FINALES DEL SIGLO XX
}

\author{
Julio DÍAZ DÍAZ \\ Centro de Educación de Adultos de Santander (España) \\ di.jul@hotmail.com
}

Resumen: Estudio de las revistas culturales, antologías y colecciones de poesía surgidas en Cantabria (España) entre 1990 y 2000. Se analizan sus características de edición y se destacan sus promotores y patrocinadores.

Abstract: A study of the cultural journals, anthologies and poetic collections found in Cantabria (Spain) between 1990 and 2000. Edition characteristics are analysed, high lighting their sponsors and promoters.

Palabras clave: Colecciones Poéticas. Cantabria. 1990-2000

Key Words: Poetic Collections. Cantabria. 1990-2000 


\section{REVISTAS CULTURALES}

Durante la última década del siglo XX, las revistas culturales surgidas en Cantabria adoptan comúnmente un formato en el que se combinan la información, el comentario crítico, el ensayismo histórico y los debates acerca de los grandes temas de interés social y cultural. Por lo general, son publicaciones que presentan un inequívoco sello de cosmopolitismo intelectual, que buscan un lector de nivel cultural medio-alto e interesado en un mundo cambiante y sometido a grandes transformaciones y retos históricos.

Es indudable que la poesía, como expresión comunicativa singular y como referencia estética de su tiempo, alcanza en estas revistas un rango casi de privilegio. Sin duda en ello influye el hecho de que la mayoría de los responsables, coordinadores o promotores de tales proyectos editoriales son poetas o personas vinculadas estrechamente a la creación poética (Carlos Alcorta, Rafael Fombellida, Juan A. González Fuentes, Regino Mateo, Antonio Montesino, Lorenzo Oliván, Ángel Sopeña).

Altazor (Revista literaria) surge en 1992, con una línea de redacción ambiciosa, que pretende:

establecer un fecundo equilibrio entre lo autóctono y lo cosmopolita; entre España e Iberoamérica; entre tradición y vanguardia; crítica y creación; escritores conocidos y noveles; $y$, en definitiva, atraer la atención del lector culto y también la del que sólo esporádicamente se interesa por la literatura (Cabrales, 1992: s. p.).

Dirigida y coordinada por el catedrático José M. Cabrales y el poeta Ángel Sopeña, esta revista marca un modelo de edición que será muy común en la mayoría de las publicaciones de estas características en Cantabria: el ensayo humanístico (en este caso orientado mayoritariamente hacia el mundo literario), comentarios de carácter crítico-estéticos y creaciones literarias y artísticas.

Tras seis números publicados, Altazor se da por desaparecida en 1994, tras la fuerte crisis desatada en las instituciones regionales y la consiguiente merma en los fondos destinados a publicaciones de interés cultural. Con la desaparición de esta revista, y a criterio de su director, se pierde «una referencia importante para los creadores e investigadores de la región, convertida de nuevo en la única autonomía sin voz literaria propia» (Cabrales, 1996: $16)$. 
La revista Pluma y Pincel surge en 1993 como órgano de comunicación e información de la Tertulia de la Asociación Cultural Goya de Santander. Está dirigida por Luis Movellán Iglesias y cuenta con una subvención del Gobierno regional y el Ayuntamiento de Santander. Al tratarse, en realidad, de una publicación vinculada a una asociación, el perfil editorial mantiene un carácter muy general y centrado en contenidos puramente informativos y recreativos. No obstante, en sus páginas siempre ha tenido un lugar preferente la poesía, bien a través de los diferentes certámenes convocados, bien con muestras creativas aportadas por colaboradores y lectores.

Con la fundación en 1996 de La Ortiga (Revista cuatrimestral de arte, literatura y pensamiento) se crea el más ambicioso proyecto editorial y de debate cívico-crítico en Cantabria. El proyecto está respaldado por un grupo de personas independientes política e ideológicamente. La iniciativa editorial y cultural, inscrita bajo el sello de la Editorial Límite, acabará perfilándose en un proyecto que reagrupará la revista cuatrimestral y, además, tres colecciones de libros dedicadas al ensayo, a la poesía y a la narrativa. La polifacética personalidad de su fundador Antonio Montesino - poeta, editor, antropólogo, ensayista e investigador social - resulta clave para llegar a comprender esta empresa cultural, que pretende convertirse en una referencia en el ámbito intelectual de España. La Ortiga contó desde un principio con las colaboraciones y aportaciones de algunos pensadores o creadores de la talla de Fernando Savater, Gustavo Martín Garzo, Leopoldo M. Panero, José Saramago, Emilio Lledó o José Á. Valente.

También en el año 1996 se funda Componente Norte (Revista de arte, literatura y humanidades). Promovida y financiada desde el Gobierno regional y coordinada por Juan A. González Fuentes, esta publicación de carácter anual pretendió convertirse en la revista de referencia en el ámbito cultural e intelectual de Cantabria, una vez desaparecida Altazor. A diferencia de la revista que dirigía José M. Cabrales, la edición de Componente Norte se realizó con mayor dotación en recursos humanos y en medios materiales. Los contenidos de Componente Norte se perfilaban en cuatro secciones - en la mayoría de los casos fijas - dedicadas al comentario y al ensayo («Arquitectura», «Cine», «Artes Plásticas», «Fotografías»), un informe o «dossier» sobre algún tema de especial actualidad (como el dedicado a «El 98 en Cantabria» en el número correspondiente a 1998), y una última sección orientada propiamente hacia la creación literaria.

Ultramar, Revista de literatura y arte nace en Santander en 1997. Es una iniciativa de tres poetas de Cantabria (Carlos Alcorta, Rafael Fombellida y 
Lorenzo Oliván), y cuenta con el apoyo financiero de la Consejería de Cultura y el Ayuntamiento de Santander. Ultramar mantiene el doble objetivo de dar a conocer en el exterior la poesía que se hace en Cantabria y, a la inversa, dar a conocer en Cantabria las líneas y creaciones poéticas que se desarrollan en España. Por sus páginas han aparecido poetas como José Gutiérrez, José Luis Puerto, Álvaro Valverde, Vicente Gallego, Clara Janés, Jaime Siles o Miguel D’Ors. En su última época, la revista publica también pequeñas ediciones monográficas, dedicadas a autores destacados en el panorama poético nacional.

La revista Espacio Único nace en Santander en 1996 de la mano de Regino Mateo y de un grupo de universitarios, cuyo vínculo de unión residía en haber concursado y haber resultado ganadores en algunas de las convocatorias del premio «Consejo Social de la Universidad» Los dos únicos números de Espacio Único (otoño e invierno de 1997) pretenden constituirse en «un punto de encuentro común a las diversas generaciones literarias, a las diferentes opciones estéticas sin exclusiones dogmáticas y academicistas» (Mateo, 1997: 9).

El único número publicado de Águeda puede considerarse como la primera iniciativa editorial protagonizada por los más jóvenes poetas cántabros de fin de siglo. En noviembre de 1996 (coincidiendo con la muerte de Charles Bukowski), un grupo de adolescentes y jóvenes universitarios (Jorge Oceja Castanedo, Jesús Bárcena, Vicente Gutiérrez Escudero), sacan a la luz una pequeña publicación totalmente artesanal y con un diseño muy ceñido y sucinto.

(H)ALA! Revista de palabras nace en 1998 como una publicación también artesanal y comprometida con la poesía más joven y radical en ese momento. Coordinada y dirigida por Raquel Serdio, Arsenio González y Alberto Muñoz, esta publicación es también la única que se edita fuera del ámbito geográfico y cultural de las ciudades de Santander y Torrelavega.

El destino de la mayoría de las revistas literarias fundadas a finales del siglo XX en Cantabria ha estado marcado por la escasez de recursos, la variabilidad en las políticas editoriales y el cansancio y agotamiento de los propios promotores. Tan sólo La Ortiga y Ultramar han conseguido traspasar el primer lustro del nuevo mileno, y lo han hecho con una estrategia editorial que, en cierto modo, resulta una garantía para su supervivencia. En esencia, se trata de un tipo de revista con un cierto aire de «cosmopolitismo» e independencia intelectual, volcada hacia el exterior y que no se deja lastrar por 
«lo autóctono» o «regionalista». Un modelo de revista en permanente comunicación con la realidad cultural, que aspira a integrarse en proyectos intelectuales o artísticos de ámbito nacional e internacional. Una revista -en fin-cuyos promotores son a la vez personas con amplia experiencia en el mundo de la creación literaria y la edición cultural.

\section{COLECCIONES POÉTICAS}

En 1993, se funda, en Santa María de Cayón, La Sirena del Pisueña, la colección de poesía más consistente y mejor editada en Cantabria a finales del siglo Xx. Con el apoyo financiero de la institución municipal de Cayón, el catálogo está dirigido por Luis Malo Macaya y coordinado por Fernando Gomarín. La línea de edición se centra en autores cántabros de muy diferentes estilos y generaciones. Por ello, esta colección se convierte en un fiel exponente de la pluralidad creativa en la región a finales del siglo: desde las antiguas poéticas de posguerra (Rodríguez Alcalde, José Hierro), los autores rehabilitados de preguerra (Manuel Llano), pasando por algunos de los nuevos nombres en poesía (Regino Mateo, Yolanda Soler). También tienen cabida en las páginas de la colección las muestras poéticas de autores «trasterrados» y alejados de la región como Jesús Pardo y Arturo del Villar.

La Sirena tiene continuidad, a partir de 2004, con las ediciones de los Pliegos de poesía «Son de Sirena», también bajo el apoyo del municipio de Cayón y con la misma dirección editorial. Estos pliegos constituyen, en realidad, muestras y «adelantos» de poemarios completos. A través de ellos, se pretende promocionar a los poetas jóvenes «poco consolidados y a algunos no tan jóvenes, pero con un historial que merece la pena [...]» (Gomarín, 2004: 55).

La colección Árgoma surgió de la iniciativa particular de Gonzalo Román y tuvo como primera finalidad reivindicar la figura y obra del poeta cántabro Carlos Salomón: «Contribuir a recuperar del olvido a un creador tan significativo tanto por su obra como por haber sido el primer promotor de Proel, la más importante aventura literaria y artística que ha protagonizado un grupo de poetas de esta tierra» (Román, 1997: III). Por ello, el primer número de la nueva colección será La brevedad del plazo, poemario original de Salomón y mecanografiado por el propio poeta cántabro unos días antes de su repentina muerte, acaecida en 1955.

Entre los propósitos y objetivos que traza Gonzalo Román para su colección están precisamente el conseguir reunir dentro de un mismo catálogo 
a autores «locales» y a algunos escritores de relevancia en el contexto nacional e internacional. De este modo, se pretende ampliar los cauces creativos y evitar los encasillamientos localistas: «Aspiramos a que el nombre de los creadores de esta tierra tenga una mayor proyección y gocen de la máxima difusión. Y esto sólo se puede lograr con una colección abierta. Si nos redujéramos a nuestros poetas locales, sufrirían éstos una limitación y un aislamiento imperdonable» (Román, ibidem).

Los dos primeros números de Árgoma corresponden a una traducción de Le poéte fou, del escritor francés Pierre Emmanuel, que sale a la luz en la versión de L. Rodríguez Alcalde y bajo el título de El poeta demente (Cantos a Hölderlin), en 1996. Un año después, se publica el poemario hasta entonces inédito de Carlos Bousoño, El martillo en el yunque, e igualmente Revelación en Patmos de Gómez de Tudanca.

La colección de poesía HUMUS surge en 1997 de la mano del joven poeta Vicente Gutiérrez, quien de este modo pretende lograr «un espacio de referencia y encuentro para los diferentes autores noveles que pretenden abrirse camino. Gracias a HUMUS se ha logrado dar cabida a poetas que no la tendrían, en principio, en otros medios de difusión más generales» $(\mathrm{Gu}-$ tiérrez et al., 1997: 9). Esta colección se convierte decididamente en plataforma para la «nueva estética», y es una muestra de la nueva sensibilidad con que irrumpen los más jóvenes poetas cántabros a fines de siglo. Con la publicación de la antología del mismo nombre en 2003 — esta vez ya en coordinación con Alberto Santamaría - se consolida el proyecto editorial y se completa el deseo de estos jóvenes en dar a conocer la nueva poesía que se venía haciendo en la región desde diez años atrás.

La colección El gato de Cheshire surge, en 1999, merced a la iniciativa particular de Regino Mateo y sin ningún tipo de apoyo financiero o editorial. El primero de los números editados corresponde a De sombras (y alguna penumbra), escrito por Gloria Ruiz e ilustrado por Esteban de la Foz. Se trata de un poemario ya editado en parte a través de la galería Trazos Dos, y que viene a ser el octavo de los poemarios de la veterana poeta cántabra. A continuación se publican, también en el mismo año de 1999, Desviaciones y demoras de Abraham Gragera y Verso y reverso de la urbe de J. A. Pérez del Valle. Al ser un proyecto de carácter personal, el futuro de esta colección depende exclusivamente de la disponibilidad económica de su promotor y director.

Otros proyectos de colecciones surgidos a finales del siglo nacen también bajo la propuesta particular de algún editor y con una idea ya predetermina- 
da de publicación. Su futuro está condicionado por las posibilidades de edición y demanda. Tal es el caso de la iniciativa de Saiz Viadero, cuya colección Guiomar pretende dar a luz la poesía específicamente escrita por mujeres, a través de la editorial Tantín. Hasta el momento, han salido al mercado Cien raíces para quedarse (1999) de Rosario de Gorostegui, y otros tantos poemarios más de Natalia Liaño (Retazos en azul, 1999) y Adela Sainz Abascal (Al final de las horas muertas, 2002).

\section{ANTOLOGÍAS}

La última década del siglo XX coincide en Cantabria con el auge en la publicación de antologías poéticas de variado signo y características. En todos los casos el criterio del editor o de la empresa editorial es el que, a la postre, decide el sentido o tendencia de cada antología y el propósito con el que sale al mercado. Por ello, la tipología de estas publicaciones resulta muy heterogénea, y su análisis y catalogación revisten diferentes modos de acercamiento, en función de las diversas variables que intervienen en el proceso de edición ${ }^{1}$.

Durante la década de los noventa, las ediciones de antologías que tienen como protagonista un solo autor - antologías de carácter individual - son muy contadas. En la mayoría de los casos, se trata o bien de poetas cántabros ya fallecidos y que tienen ya la consideración de «clásicos del siglo XX», o bien de autores veteranos y que gozan de un gran prestigio y consideración en el ámbito cultural de la región. En casi todas las ocasiones, son las propias instituciones públicas las que financian y promueven este tipo de ediciones, consideradas de alto interés cultural y literario.

El hecho de que el último decenio del siglo XX coincida con el fin de centuria y milenio constituye, en muchos casos, un elemento decisivo para dar a conocer las mejores muestras de la poesía hecha en Cantabria. Por ello, se presentan ante los lectores como manifestaciones del espíritu creativo y singular de algunas de las más insignes personalidades del mundo cultural de la región. Otras veces, la oportunidad de editar el libro se origina a partir de algún tipo de conmemoración, homenaje o celebración especial, que acaba convirtiéndose en una ocasión propicia para conocer o difundir la obra del poeta en cuestión.

1 Para este estudio sobre las antologías, adapto los criterios metodológicos y de clasificación que ha establecido Julio Neira (2002). 
El catálogo bibliográfico de autores ya clásicos en la poesía del siglo XX, como José Luis Hidalgo, Gerardo Diego y José Hierro, aumenta considerablemente durante el último decenio del siglo, gracias a numerosas reediciones de algunos de sus mejores libros, o bien a través de recopilaciones en forma de «poesía u obra completa». Sin embargo, en Cantabria son muy contadas las ediciones de estos autores bajo el formato específico de «antología».

La Antología poética de Gerardo Diego, publicada en 1996, constituye la muestra más densa, rigurosa y completa de todas las ediciones realizadas en Cantabria, dedicadas a este autor. Con selección del profesor Juan Carlos Temprano, introducción de José Hierro y estudio bibliográfico de José Luis Bernal, esta antología reúne poemas tomados de los mejores libros y de todas las etapas estéticas en la dilatada vida de Gerardo Diego: desde Imagen, Poemas (1918-1921) (Madrid, 1922) hasta Odas morales (Málaga, 1986).

Las características y particularidades de edición hacen de esta Antología poética de 1996 una muestra de lo que podría considerarse la «antología definitiva» de un autor considerado esencial en la literatura española contemporánea. La combinación de una cuidada selección literaria y un estudio crítico-bibliográfico completo, riguroso, y a la vez dirigido a un público no especializado, constituyen las notas más singulares y relevantes de esta edición, que puede considerarse «modélica» en muchos aspectos.

El recientemente fallecido Leopoldo Rodríguez Alcalde es considerado como otro de los clásicos de la poesía en Cantabria en la centuria pasada. Su trayectoria literaria e intelectual se ha prolongado durante cerca de cincuenta años, en una actividad creativa casi incesante. La edición de su obra poética selecta se realiza en Madrid en los últimos años del siglo XX, a través de la edición de Canciones para una biografía: poesía, 1948-1993 (Aldebarán, 1995). En Cantabria, es la Diputación Regional la que se encarga de reunir en un único libro toda su producción poética entre 1948 y 1978, bajo el título de Jugando a la vida. Poesía completa.

A diferencia de la antología dedicada a Gerardo Diego, en este caso el aparato crítico o bibliográfico es absolutamente nulo, y -más que de selección poética- hemos de hablar de una recopilación de la obra lírica que Rodríguez Alcalde escribió entre los años mencionados. Es esta falta de información bibliográfica y crítica la que impide saber al lector si tal recopilación se hace tomando como base sus libros editados o publicados en su momento, o si se trata de otras series poéticas hasta entonces inéditas o desconocidas 
(como es el caso de Ante algunas imágenes, Un silencio con toda el alma y Tríptico de la bahía). La falta de cuidado en la edición es tal que ni siquiera consta el año de publicación o composición de los diferentes libros editados y más conocidos de Rodríguez Alcalde ${ }^{2}$.

Un caso muy diferente es Antología final. Poemas, 1949-1996 de Jesús Pardo, otro de los ilustres veteranos de las letras en Cantabria. En este caso, tenemos una antología propiamente de autor-editor. La selección poética se ha hecho personalmente, con el máximo cuidado y tratando de reunir en un mismo formato de edición las mejores composiciones de sus dos poemarios publicados (Presente vindicativo estrictamente epidérmico, Madrid, 1977; y Faz de las fauces del tiempo, Madrid, 1983). Además, el libro se complementa con una treintena de «Otros poemas» hasta entonces inéditos, el último de los cuales lleva fecha de 1996. La antología conserva un carácter recopilatorio y a la vez conmemorativo de toda la larga trayectoria literaria de Pardo. En algunos casos, las composiciones han sido sometidas a un proceso de reescritura y —en palabras del poeta — tan corregidas «que casi es obra nueva» (el poema que lleva por título «Santander» — publicado por primera vez en el último número de la revista La Isla de los Ratones-es un buen ejemplo de ello).

En cuanto a lo que se refiere a las antologías de carácter colectivo, los criterios en la selección de autores y poemas escogidos dependen en gran medida del planteamiento crítico y metodológico que sigue la persona encargada de llevarla a cabo. En este sentido, la variabilidad que encontramos es grande en cuanto a las características, contenido y fines que persigue cada una de las publicaciones: bien sea de carácter temático, geográfico, cronológico $\mathrm{o}$, más bien, de índole general. (Cf. Neira, 2002: 551 y ss.). Sin embargo, no es fácil encontrar durante el mismo período alguna publicación de estas características en función de un criterio propiamente genérico y con una determinada estructura expresiva y formal. Todos los Sonetos de José Hierro (Ayuntamiento de Santa María de Cayón, 1995), que recogen la mayor parte de las creaciones de este tipo, escritas entre 1939 y 1993, están entre las pocas excepciones de antología genérica y — en ese caso- de carácter individual.

\footnotetext{
${ }^{2}$ En los casos en que aparece alguna reseña cronológica infunde a fácil confusión; así, en el índice del libro se señalan cuatro series poéticas aparentemente independientes, con la única referencia del año de composición (desde 1948 a 1951). Con tan escasos y confusos datos, el lector no avisado difícilmente puede llegar a deducir que en realidad las cuatro series pertenecen a un único libro, y que fueron recogidas en Cancionero de Monte Corbán, editado en 1952. En la publicación no se consigna ni se manifiesta, implícita o explícitamente, el responsable de la edición.
} 
En muchas ocasiones, la catalogación o descripción de las antologías no puede en realidad hacerse de manera uniforme y sistemática, sino más bien atendiendo a criterios variados y diversificados en cuanto a la selección de autores y poemas. Por ello, se pueden encontrar publicaciones en las que los criterios de edición responden a varios factores a la vez y no específicamente a uno solo; o al revés, puede existir uno de ellos que se considera básico, irrenunciable y primordial para que puedan formalizarse o aplicarse otro tipo de consideraciones más particulares.

El criterio geográfico, por ejemplo, resulta ser el aglutinante y el factor común en la mayoría de las antologías publicadas inmediatamente a partir de 1976. Tal particularidad se refuerza durante el proceso político autonómico que precedió a la instauración del Gobierno regional, con la consiguiente reactivación del interés popular en las manifestaciones culturales de carácter autóctono o tradicional. Pero, al final de la centuria, ese interés decrece considerablemente entre los editores y lectores de poesía.

Las antologías editadas al cuidado de alguna persona especializada o entendida en este tipo de materia, suelen caracterizarse por un conjunto de marcas distintivas y por una impronta especial en cuanto a organización y tratamiento literario. En la mayoría de las ocasiones, en Cantabria esta labor la ejercen reconocidos críticos o investigadores, que aportan sus propias visiones y maneras de acercarse a la poesía. En todo caso, la claridad en los criterios, la solvencia intelectual y la pericia del editor resultan indispensables para distinguir una verdadera antología de lo que podría entenderse como una mera «agrupación compilatoria». Así lo entiende José Ramón Saiz Viadero al analizar y valorar algunas ediciones colectivas de poesía en Cantabria, tales como Obertura en el Norte (Barcelona: PPU, n. 3, 1988) o Laberintos del Verso en la ciudad inerte (Siete estados de resurrección) (Santander: Tantín, 1988): «Ninguna de estas dos obras colectivas responde al criterio de antología, ni pretende serlo; simplemente son formas de agrupar los trabajos de diferentes creadores líricos que unen sus esfuerzos para hacer llegar sus obras a un mayor número de lectores» (Saiz Viadero, 1997: 13).

No obstante, y llegados a este punto, resulta conveniente señalar que entre las personas que más se han distinguido en la elaboración y edición de antologías poéticas en Cantabria, es habitual la creencia y convicción de que no existe la «antología perfecta» y definitiva. Existen unos límites ineludibles en lo que se refiere a condiciones o posibilidades «técnicas» y literarias de edición (a saber: posibles lectores, segmentación temporal aplicable y espacio geográfico de referencia) (Cf. Saiz Viadero, 1999: 9). 
Por otro lado, y aparte de los criterios considerados «objetivos», es lógico pensar que en cualquier tipo de selección siempre se dejan ver las perspectivas, gustos personales y preferencias estéticas. También es cierto que lo que podría llamarse «efecto de Fin de Siglo», y la tendencia a considerar esta época como un momento único y ya «cerrado» a efectos de creatividad artística y literaria, fomentan un cierto tipo de prisas y urgencias «recopilatorias» $\mathrm{y}$ «selectivas», que casi nunca son buenas para conseguir una edición correcta y bien diseñada. Por otro lado, este tipo de particularidades no siempre se corresponde con la inercia natural en la evolución de los diferentes procesos estéticos, ni con las formas de pensamiento y creación de los escritores que se están iniciando precisamente en ese mismo período. Los poetas más jóvenes, y con unas perspectivas creativas decididamente «abiertas» $\mathrm{y}$ «expectantes» ante el futuro, se sienten más interesados en ofrecer a los lectores un proyecto literario en desarrollo o un manifiesto creativo-poético, en lugar de una recopilación antológica estéticamente conclusa y conformada. El espíritu que anima a los editores de la colección y antología $H U$ $M U S$, ya comentada anteriormente, puede resultar un buen referente de todo ello.

Saiz Viadero es uno de los editores-críticos que más antologías poéticas ha preparado en esta década de los noventa en Cantabria. En todas ellas, se evidencian unos criterios y una finalidad editorial específica. Sin embargo, en la mayoría de los casos subyacen dos tipos de realidades o motivaciones, especialmente reiteradas en los proyectos editoriales de este investigador y crítico santanderino: mostrar las novedades y tendencias creativas que aportan las últimas promociones de poetas en Cantabria, y poner de relieve el papel de las mujeres en la historia de la poesía en la región.

Santander, mar y poesía, editada en 1991, resulta una antología «declaradamente» temática y centrada en recoger —en palabras del propio Saiz Viadero- «las voces de poetas que han cantado el entorno de la bahía santanderina» (Saiz Viadero, 1997: 9). Los veinticuatro poetas representados en el libro — de diferentes épocas y procedentes de diversas partes de Españareflejan otras tantas sensibilidades y modos de acercamiento estético y emocional al litoral santanderino; desde Enrique Menéndez y Pelayo, Francisco Vighi o Gerardo Diego, hasta Miguel de Unamuno, José Agustín Goytisolo o Ángel Sopeña.

Poetas de Cantabria. Años 80, publicada en 1992, es el octavo número de la colección «Historias de Cantabria». Se trata de una monografía de formato medio que edita la editorial Tantín, dirigida por el propio Saiz Viadero. La 
publicación dedica la mayoría de sus páginas a analizar y resaltar la presencia de una nueva promoción de jóvenes poetas en la región. Los poetas seleccionados son: Néstor Carmona, Rafael Pérez Llano, Marián Bárcena, M. ${ }^{a}$ Sandra García Montes, Yolanda Soler Onís, Guillermo Balbona, Ana Fernández Díaz, Regino Mateo, Juan A. González Fuentes, Ana Isabel García Burgos, Lola Camús, Miguel Ibáñez de la Cuesta, Arancha García Burgos. Casi el 50 por ciento de los autores representados son mujeres; una proporción insólita hasta entonces en una publicación de estas características. Por ello, puede entenderse esta particularidad como un proceso de «normalización» de la presencia de la mujer en la poesía de la región.

Historia y antología de la poesía femenina en Cantabria (1997) viene a ser la mejor y más amplia muestra de esa sensibilidad e interés de Saiz Viadero por la poesía escrita por mujeres. Editado en el marco de las «primeras jornadas institucionales por la igualdad de oportunidades» organizadas por la Asamblea Regional de Cantabria, el libro sale con el claro objetivo de demostrar que: «La palabra poética es eficaz, es siempre útil para confirmar o cambiar nuestra percepción de las cosas» (Saiz Viadero, 1997: 9).

La selección poética preparada por Saiz Viadero responde - como su mismo título enuncia - a una verdadera «historia y antología», en el sentido de que se atiene a una única fórmula de edición. En ella, se pretende integrar orgánicamente aspectos historiográficos, fundamentación crítica y —naturalmente- la obra poética escogida. Con todo, el hecho de que sean las mujeres poetas las verdaderas y exclusivas protagonistas de esta selección antológica constituye una nota verdaderamente singular y relevante en la historiografía literaria de Cantabria.

En Nueve novísimos de la poesía en Cantabria, el editor persigue como objetivo «reunir a una serie de poetas y dar a conocer su breve obra, tanto por medio de los recitales organizados con esa misma intención como con la publicación de sus composiciones» (Saiz Viadero, 1998: 5). La idoneidad del título le viene dada al editor por la «oportunidad y sonoridad del propio enunciado», en alusión a la famosa antología de Castellet. En todo caso, se reseña expresamente que la publicación no pretende establecer ningún tipo de criterios estéticos o generacionales, ni adelantar líneas de creación homogéneas de los autores como grupo organizado. Los nueve poetas seleccionados se consideran procedentes de «dos generaciones diferentes». En realidad se trata de autores nacidos entre 1960 y 1977, que — salvo dos de ellos- han conseguido ganar algún galardón en las convocatorias y premios de poesía que organizan tres instituciones sociales o culturales radicadas 
en la ciudad de Santander: la Consejería de Cultura, el Consejo Social de la Universidad y el propio Ayuntamiento. En la nómina de autores seleccionados figuran: Ana García Negrete, A. Belén Rodríguez de la Robla, M. ${ }^{a}$ Luisa Campo, Natalia Liaño Rincón, Antonio Fernández San Emeterio, Adela Sainz Abascal, Rosario de Gorostegui, Vicente Gutiérrez Escudero y Maribel Fernández Garrido.

En homenaje a José Hierro (Saiz Viadero, 1999) —la última de las antología que este editor santanderino prepara al final del siglo - tiene un motivo temático y emotivo muy específico: recoger «una serie de aportaciones poéticas originales, destinadas a homenajear la personalidad de José Hierro, con ocasión de la entrega de la Medalla de Oro de la Ciudad por parte del Ayuntamiento de Santander, el día 5 de noviembre de 1999» (Saiz Viadero, 1999: 9). Todos los autores seleccionados recibieron en su día alguno de los galardones que llevan el nombre del ilustre poeta desde 1982, además de los que lo consiguieron ya bajo el título de «Premio Alegría». Se pone énfasis en considerar que la antología es:

lo más representativa posible del espíritu de juventud, originalidad y calidad que animó en su día a los impulsores de los premios a hacer las convocatorias bajo el nombre de un poeta que siempre se ha distinguido por su atenta y comprensiva mirada para todo lo que proceda de las nuevas generaciones de creadores, máxime si son de su propia tierra (Saiz Viadero, ibidem).

Los autores seleccionados para la edición de En homenaje a José Hierro han nacido entre 1958 y 1977 y pertenecen a las dos promociones poéticas del fin de siglo. Cada uno de ellos firma en la antología un único poema, expresamente dedicado a la figura y obra de José Hierro: C. Alcorta, G. Balbona, M. Bárcena, M. Calvo, M. Díez Manrique, M. Fernández Garrido, A. Fernández San Emeterio, Ana I. García Burgos, Arancha García Burgos, J. A. González Fuentes, R. de Gorostegui, M. Gurruchaga, V. Gutiérrez Escudero, G. de las Heras, N. Liaño Rincón, R. Mateo, R. Pérez Llano, Luis. M. Quesada, A. B. Rodríguez de la Robla, D. Romero, A. Sainz Abascal, J. San José y Y. Soler Onís.

El motivo y los objetivos que llevan a Luis A. Salcines a editar, en 1996, la antología Poetas de Cantabria en el aula continúan siendo los mismos que el propio editor establecía dieciocho años antes, en su antología Poetas de Cantabria hoy: las intervenciones de poetas en ciclos de recitales organizados al efecto. Se resalta el hecho de que en las dos antologías, los autores representados pertenecen a estéticas diferentes y han recorrido casi todas las 
épocas creativas desarrolladas en Cantabria durante la segunda mitad del siglo XX. En todo caso, la antología Poetas de Cantabria en el aula se fija desde un punto de vista crítico e historiográfico muy bien perfilado. La inclusión y ordenamiento de autores se hace con un criterio diacrónico, poniendo siempre de relieve las características y aportaciones de sus obras dentro del desarrollo de la poesía en Cantabria durante toda la segunda mitad de la centuria. En total son dieciocho los poetas representados, cuyas fechas límite de nacimiento abarcan más de cuarenta años: desde 1926 (Pérez del Valle) hasta 1968 (Lorenzo Oliván).

Las antologías de carácter colectivo, editadas sin el cuidado de una persona especialmente encargada de ello, no aportan en la mayoría de los casos ningún tipo de aparato crítico ni estudio preliminar en cuanto a criterios específicos y organizativos. No obstante, suele mencionarse - $\mathrm{o}$ al menos intuirse fácilmente - el relieve temático o la motivación literaria en la forma y presentación de los contenidos poéticos. Los motivos conmemorativos o de homenaje suelen ser los más comunes en las ediciones colectivas de este tipo en Cantabria durante el último tramo del siglo XX.

Los premios de poesía y de narración breve que el Ayuntamiento de Santander convoca bajo el nombre de «José Hierro» cumplen en 1991 su décima convocatoria. Tal evento motiva la publicación de Premios José Hierro. Antología diez años (1982-1991), en la que figuran reunidos los primeros premios de cada edición, tanto en poesía como en relato breve, y al margen de los otros galardones o reconocimientos correspondientes en forma de accésit. Por tanto, más que de una antología se puede hablar de una verdadera recopilación y reedición de los primeros premios, a no ser que por selección «antológica» se entienda en este caso la premeditada agrupación de los autores y poemas que resultaron ganadores en las diferentes convocatorias del Premio. Los poetas incluidos son R. Pérez Llano, J. Pérez Iglesias, J. San José Lera, M. José Uslé, M. Bárcena, Y. Soler Onís, A. Fernández Díaz, M. Sánchez Calderón, E. García Alonso y R. Mateo.

Espacio único. Versos y prosas para Manuel Arce (Universidad de Cantabria, 1996) puede entenderse como una antología de homenaje a la labor y figura del veterano escritor y galerista cántabro. Más que una edición «dedicada» expresamente a ensalzar la figura y obra de una personalidad relevante (como ocurre En homenaje a José Hierro) debe entenderse como un libro «ofrecido» a Manuel Arce, en reconocimiento —en este caso- a su labor y dedicación a dichos premios universitarios, que fueron fundados y organizados precisamente por el propio escritor santanderino. En total son once poetas 
los representados en la antología y que resultaron ganadores de algún galardón en las ediciones convocadas entre 1989 y 1995: Marián Bárcena, Marina Gurruchaga, María José Echevarría, Regino Mateo, Ana María Fontalba, Juan A. González Fuentes, Ismael Rodríguez Domínguez, Silvia Megoya, José A. Santos Cuenca, José A. Gómez Cristóbal y Marcos Rebollo Fidalgo.

Poesía española del medio siglo. La Isla de los Ratones (Caja Cantabria, 1999) presenta tres aspectos o relieves en cuanto a la distribución de contenidos. Es una publicación conmemorativa del cincuentenario de la revista poética fundada por Manuel Arce, y es también un libro recopilatorio de las diferentes ponencias presentadas y expuestas en el ciclo de conferencias «Un escenario poético para la Memoria Histórica». También puede interpretarse como una antología de poemas de autores cántabros que se dan a conocer en las dos últimas décadas del siglo (C. Alcorta, Adela Saiz, R. Fombellida, G. Balbona, M. Ibáñez, V. Gutiérrez Escudero, M. Fernández Garrido y R. Mateo). La gran novedad que aporta este libro, dentro del conjunto de las antologías poéticas que se editan en Cantabria, radica en que cada poeta realiza dos tipos de aportaciones diferenciadas pero complementarias: un breve ensayo crítico sobre su propia obra poética (concepción de la poesía, criterios estéticos, compromisos sociales y personales, valoración de la actividad creativa en España y particularmente en Cantabria, etc.) y una pequeña muestra de sus realizaciones poéticas.

Mar de fondo. Antología de poesía última en Cantabria (López, 1996) y Norte y Sur de la poesía española contemporánea. Santander-Málaga (Neira, 2000) son dos antologías orientadas a dar a conocer y divulgar la obra y el pensamiento creativo de los poetas más reconocidos y significativos en Cantabria en las dos últimas décadas del siglo. Los responsables de la edición son Dámaso López y Julio Neira, dos profesores universitarios madrileños, ligados a Cantabria por lazos profesionales, personales o familiares. Las dos antologías mantienen una línea de edición actualizada, y se acercan al diseño y formato característico en las publicaciones de este tipo más relevantes en España a partir de $1985^{3}$.

Las dos ediciones cuentan con un ensayo introductorio firmado por el responsable y coordinador de la publicación, un pequeño estudio y análisis crítico de cada poeta acerca de su propia obra, y finalmente una selección de poemas reunidos para la ocasión por cada uno de sus autores. En el caso de

3 Tal es el caso de las antologías que han preparado J. L. García Martín (1988 y 1999) o Juan Cano Ballesta (2001). 
Mar de fondo, el ensayo inicial corresponde a un estudio crítico en torno a la creación poética en Cantabria durante las dos últimas décadas del siglo, y con especial incidencia en algunas de las características o peculiaridades estéticas de los autores representados.

Ambas antologías constituyen una muestra de la diversidad y pluralidad de visiones estéticas en las promociones poéticas de Cantabria a finales de siglo. Pero también resultan un referente bibliográfico de primera mano para conocer los criterios de análisis y las autovaloraciones en materia estética y creativa de los autores seleccionados, así como su propio pensamiento en torno a la poesía como fenómeno de expresión y comunicación. De igual modo, resulta un valor añadido y de interés en estas antologías el hecho de que las referidas ediciones salen al mercado justamente al final del siglo y milenio, un período en el que la mayoría de los poetas seleccionados entran en su madurez personal y creativa.

\section{REFERENCIAS BIBLIOGRÁFICAS}

\section{a) Estudios}

CABRALES, J. M. (1992). «Editorial». Altazor. Santander: Gobierno de Cantabria, 1, s. p.

- (1996). «El año editorial». Anuario de Cantabria. 1995. Santander: Editorial de Cantabria, 16.

DÍAZ. J. (2004). «La poesía en Cantabria entre 1976 y 2003 (Aspectos creativos y estéticos en la poesía de fin de siglo)». En Tiempo de poesía. La creación poética en Cantabria (1977-2004), J. A. González Fuentes y L. A. Salcines (eds.), 32-67 Santander: Caja Cantabria.

GOMARÍN, F. (2004). «Un puro errar de Vicente Gutiérrez». Alerta (Santander), 10-octubre, 55.

GUTIÉRREZ, V.; BALBONTÍN, S.; GUERRA, D.; SERDIO, R. y SANTAMARÍA, A. (2003). «Diez años de poesía última en Cantabria», G. Balbona. El Diario Montañés (Santander), 16-febrero, 86.

LÁZARO SERRANO, J. (1985). Historia y antología de escritores de Cantabria. Santander: Estudio.

— (1993). «Un futuro prometedor». Anuario de Cantabria. 1992. Santander: Editorial Cantabria, 30. 
MATEO, R. (1997). «De primera...». Espacio Único (Santander), Invierno, 9.

MONTESINO, A. (2004). «La aventura editorial de La Ortiga». Santander: Charla-Coloquio, 2 de noviembre.

NEIRA, J. (2002). La edición de textos: Poesía española contemporánea. Madrid: UNED, 551-564.

RODRÍGUEZ ALCALDE, L. (1992). «Panorama actual de la poesía en Cantabria». Altazor I, 26-30.

ROMÁN, G. (1997). «Árgoma, una colección de poesía». El Diario Montañés (Santander: Suplemento «Fin de Semana»), 6-mayo, III.

\section{b) Antologías}

ARCE, M. (1996). Espacio único. Versos y prosas para Manuel Arce. Santander: Universidad de Cantabria.

- (1999). Poesía española del medio siglo. La Isla de los Ratones. Santander: Caja Cantabria.

CANO BALLESTA, J. (ed.) (2001). Poesía española reciente (1980-2000). Madrid: Cátedra.

DIEGO, G. (1996). Antología poética. Santander: Gobierno Regional de Cantabria.

GARCÍA MARTÍN, J. L. (ed.) (1988). La generación de los ochenta. Valencia: Mestral Libros.

- (1999). La generación del 99: antología crítica de la joven poesía española. Oviedo: Nobel.

HIERRO, J. (1995). Todos los sonetos. Santa María de Cayón: Ayuntamiento de Cayón.

LÓPEZ, D. (ed.) (1996). Mar de fondo. Santa María de Cayón: Ayuntamiento de Cayón.

MATEO, R. (1996). Espacio único. Versos y prosas para Manuel Arce. Santander: Universidad de Cantabria.

NEIRA, J. (ed.) (2000). Norte y Sur de la poesía española contemporánea. Santander: Caja Cantabria. 
PARDO, J. (1997). Antología final. Poemas. 1949-1996. Santa María de Cayón: Colección La Sirena del Pisueña, n. ${ }^{\circ} 18$.

PÉREZ LlANO, R. (1991). Premios José Hierro. Antología diez años (1982-1991). Santander: Ayuntamiento de Santander.

RODRÍGUEZ ALCALDE, L. (1982). Jugando a la vida. Poesía completa. Santander: Diputación Provincial.

SAIZ VIADERO, R. (ed.) (1991). Santander, mar y poesía. Santander: Tantín.

- (1994). Poetas de Cantabria. Años 80, Historias de Cantabria. Santander: Tantín.

- (1997). Historia y antología de la poesía femenina en Cantabria. Santander: Tantín.

- (1998). Nueve novísimos de la poesía en Cantabria. Santander: Tantín.

- (1999). En homenaje a José Hierro. Santander: Ayuntamiento de Santander.

SALCINES, L. A. (ed.) (1997). Poetas de Cantabria en el aula. Santander: Tantín. 